\title{
A Facil Water Treatment Rendering Cement Kiln Dust Reusable in Clinker Manufacturing
}

\author{
Zaki MI*, Ismail HM, Mekhemer GAH and Salama HSM \\ Chemistry Department, Faculty of Science, Minia University, El-Minia 61519, Egypt
}

*Corresponding author: Zaki MI, Professor, Chemistry Department, Faculty of Science, Minia University, El-Minia 61519, Egypt, Tel: 00201202149149, E-mail: mizaki@mu.edu.eg

Citation: Zaki MI, Ismail HM, Mekhemer GAH, Salama HSM (2019) A Facil Water Treatment Rendering Cement Kiln Dust Reusable in Clinker Manufacturing. J Waste Resour Recycl 2(1): 101. doi: 10.15744/2766-5887.2.101

Received Date: July 27, 2019 Accepted Date: December 21, 2020 Published Date: December 23, 2020

\begin{abstract}
Background: Worldwide, stockpiled cement kiln dust (CKD) has been neither properly disposed, nor profitably utilized. Mostly it contains $\geq 6$ wt $\%$ alkali metal salts; therefore, it cannot be reused as a raw material in clinker manufacturing in cement industry. In the present work, a facile water treatment, before and after calcination (at 500-1000 ${ }^{\circ} \mathrm{C}$ ) of $\mathrm{CKD}$, was designed and found to help leaching out the salt content that renders CKD reusable in the clinker manufacturing.

Results: Water treatment products, as examined for compositional and morphological consequences by XRD, FTIR, SEM and EDX, were found to reveal that the water treatment applied, via stirring for as short as 15 min under ambient conditions, effectively freed $\mathrm{CKD}$ from its salt content (KCL, $\mathrm{NaCl}$ and $\mathrm{CaSO}_{4}$ ) in the form of separable flake-like crystal aggregates.
\end{abstract}

Conclusion: The proposed water treatment procedure was proved efficient in wavering CKD from its salt content thus paving the way to its reuse in clinker manufacturing, thus evolving an added value to the cement industry.

Keywords: Cement Kiln Dust; Heat Treatment; Water Treatment; Compositional Consequences; Morphological Consequences

\section{Introduction}

Cement kiln dust (denoted $\mathrm{CKD}$ ) is by-produced during the calcination process in the kiln of cement clinker manufacturing plants [1,2]. It is a massive by-product (ca. 30 million tons/year worldwide and 5-20\% of the amount of cement clinker produced [3-5]) that is generally a heterogeneous mixture by chemistry and particulate size. These characteristics are dependent on the raw feed materials, fuels, kiln pyroprocessing type (dry or wet), overall equipment layout, and kind of cement being manufactured [4,6]. Chemically speaking, however, it includes oxides, carbonates, chlorides and sulfates of $\mathrm{Ca}, \mathrm{K}, \mathrm{Na}, \mathrm{Al}, \mathrm{Fe}$ and $\mathrm{Si}$, with $\mathrm{CaO} / \mathrm{CaCO}_{3}$ being its major constituent [2]. $\mathrm{CKD}$ is separated from the clinker kiln exhaust gas in order to prevent (i) the alkali content of the clinker from exceeding the maximum allowable value $(\leq 0.6 \%)$ [7], and (ii) the buildup of excessive salts (chlorides and sulfates) in the produced clinker [7].

Only a small proportion of the generated CKD is recycled back again with the clinker, but the rest (ca. 80 \%) is stockpiled and/or land-filled thus posing significant environmental and health threats $[3,7,8]$. Hence, it is a chemical waste material that is neither properly disposed, nor profitably utilized. In Egypt, for instance, ca. one million tons of CKD are discharged annually from cement kilns [9], which contain excessive amounts of alkali compounds, thus making them unsuitable for reuse in the cement making process [5,10]. Consequently, an active research has been urged to find out profitable ways and means of using CKD, not only to avoid its environment and health threats, but also to evolve an added value to the global cement industry. This is bearing in mind, that cement is indispensably a strategic material for the ever growing construction economy [7,11]. Research-devised new applications implement CKD in (i) concrete mixes as cement substituent [6,11,12], (ii) soil conditioning and stabilization [13-17], (iii) filler material in asphalt mixes [13,15,18], (iv) the making of lightweight aggregates, blocks and bricks [7], (v) solidification/ stabilization of hazardous waste [15], (vi) wastewater treatment [9,19], (vii) heavy metal scavenging [20,21], and (viii) the making of a catalyst for the gasification of biomass [22]. Despite of their obvious diversity, these applications use-up but only a small amount of the on-site piled CKD worldwide. Hence, further research efforts are still urged to optimize utilization of CKD.

The present investigation is an attempt to join the forces with the international research endeavor in tackling this important issue. The thrust has been not only the awareness of the obvious environmental, health and economical necessities of the subject, but also the lack of in-depth knowledge about the influence of two basic treatments, namely the heat and water treatments, on the chemical composition and morphology of CKD particles. It is worth noting, in this regard, that influence of water treatment of CKD was previously examined but was focused on the hydration of the lime content into $\mathrm{Ca}(\mathrm{OH})_{2}$ in order to improve the viability of using 
it in soil stabilization [14] and wastewater treatment $[9,19,20]$ purposes. In the present investigation, however, water treatment experiments were designed to facilitate long-term (up to 14 days) processing in hopes of going beyond the hydration into the hydrolysis of a patch of a stockpiled CKD in a local cement manufacturing plant. Subsequently, the CKD and its hydrolysis (and thermolysis) products were characterized by means of thermogravimetry, X-ray diffractometry, infrared spectroscopy, scanning electron microscopy, and energy dispersive X-ray micro-probing chemical analysis. Results obtained were implemented to reveal influence of the heat and water treatments applied on the salt content of CKD and, hence, its reusability in clinker manufacturing.

\section{Experimental}

\section{CKD origin and factory provided information}

CKD sample used in the present investigation was a grayish white fine powder provided by ASECMINYA cement plant (Minya Portland/El-Minya/Egypt). It was taken from a freshly homogenized mixture that was exited at $1050{ }^{\circ} \mathrm{C}$, then quenched and cooled by fresh air, separated by means of a bag house filter, and collected in pin without any treatment, throughout a $24-\mathrm{h}$ processing. Information provided for the CKD sample included the chemical composition, mass loss on ignition (LOI) at $975{ }^{\circ} \mathrm{C}$ for $1 \mathrm{~h}$, the manufacturing kiln type and processing condition, and raw materials used, are set out in Table 1. Accordingly, the chemical composition is shown to be majored by $\mathrm{CaO}(50.25 \%)$ and $\mathrm{SiO}_{2}(14.66 \%)$, and minored by alkali metal oxides $\left(\mathrm{K}_{2} \mathrm{O}(6.64 \%), \mathrm{Na}_{2} \mathrm{O}\right.$ (3.30\%) and $\mathrm{MgO}(0.99 \%)$ ) as well as $\mathrm{Al}_{2} \mathrm{O}_{3}(4.51 \%), \mathrm{Fe}_{2} \mathrm{O}_{3}(2.9 \%), \mathrm{SO}_{3}(5.89 \%)$ and $\mathrm{Cl}(7.69 \%)$. These quantitative results are in the order of magnitude of the average of quantitative results reported for variously obtained CKD samples by Peethamparan et al. [14]. On the other hand, it was also provided that the CKD sample consists of $61 \%$ particles below $45 \mu \mathrm{m}$ diameter and $15 \%$ particles above $90 \mu \mathrm{m}$.

\section{CKD heat treatment}

Based on thermogravimetry and differential thermal analysis results (vide infra), portions of the CKD sample were calcined at 500,650 or $1000 \pm 2{ }^{\circ} \mathrm{C}$ (for $1 \mathrm{~h}$ ) in a static atmosphere of air. Therefore, ca. 10 -g portion of the loose powder was placed in widemouth porcelain crucible, admitted into an electronically controlled Naber 2804 muffle furnace (Germany) at room temperature (RT), and, then, the temperature was linearly elevated (at $20^{\circ} \mathrm{C} / \mathrm{min}$ ) to the set value. After the elapse of $1 \mathrm{~h}$, the temperature was leveled off, the calcination product was withdrawn from the furnace (at $200{ }^{\circ} \mathrm{C}$ ), and kept desiccated over $\mathrm{CaCl}_{2}$ till further use. The calcination products are discerned from the uncalcined CKD by suffixing the calcination temperature applied. For instance, the calcination product at $500{ }^{\circ} \mathrm{C}$ is denoted CKD-500 throughout the text.

\section{CKD water treatment}

Long- (LT) and short-term (ST) modes of water treatment of CKD and its calcination product at $1000{ }^{\circ} \mathrm{C}(\mathrm{i} . e ., \mathrm{CKD}-1000)$ were conducted by soaking the material particles in bi-distilled water $(1 \mathrm{~g} / 40 \mathrm{~mL})$ in a glass vessel at RT, magnetically stirring the vessel content for $15 \mathrm{~min}$, and, then, either (i) maintaining the water/solid contact at RT till complete dryness (LT mode), or (ii) separating immediately the solid particles from the aqueous medium by filtration through a filter paper (ST-mode). In the STmode, the separated wet solid and filtrate were also maintained under ambient conditions till complete dryness. The complete dryness was accomplished in both modes after 14 days. The dried products of the LT-mode were milky white crystals (aggregated in the form of large, thin flakes) settling on top of a fine powder. The crystals' flakes were large enough to be successfully manually separated from the powder. Dried crystals and powders produced via the LT- and ST-modes of water treatment were pulverized by mortar and pestle, and kept desiccated over $\mathrm{CaCl}_{2}$ till further use. It is obvious that the crystals are for water-leachable constituents of the soaked material (CKD or CKD-1000), whose growth may had been reminiscent to the slowness of both the water solvent evaporation and the consequent elevation of concentration of the leachate species at room temperature (RT). Whereas the powders are to dwell the residual solid particles. Hence, leachate crystals (L) produced via the LT-mode of water treatment of CKD are designated as $\mathrm{CKD}(\mathrm{LT} / \mathrm{L})$, whereas the residual powder $(\mathrm{R})$ produced via the ST-mode is denoted CKD(ST/R). It is worth noting, that water treatment parameters were chosen in order to help going beyond CKD hydration [14] into hydrolysis.

\section{Characterization methods}

Thermogravimetry (TG) and differential thermal analysis (DTA) were carried out on heating (at $20{ }^{\circ} \mathrm{C} / \mathrm{min}$ ) ca. 25-mg portion of test sample, in a dynamic atmosphere of air $(40 \mathrm{~mL} / \mathrm{min})$, up to $1000{ }^{\circ} \mathrm{C}$, using a model DTG-60H Shimadzu analyzer (Japan). $\alpha-\mathrm{Al}_{2} \mathrm{O}_{3}$ (Shimadzu Corp.) was the thermally inert reference material used with the DTA measurement. X-ray powder difractometry (XRD) was conducted on a model JSX-60PA Jeol diffractometer (Japan) equipped with Ni-filtered CuKa radiation $(\lambda=0.1542 \mathrm{~nm}$, $40 \mathrm{kV}$ and $30 \mathrm{~mA}$ ). Diffraction patterns thus obtained were matched with standard diffraction data filed in JCPDS cards [23] for phase composition identification purposes. Fourier-transform infrared (FT-IR) spectroscopy was carried out employing a Genesis II Thermo Mattson FT-IR spectrophotometer (USA) powered with WinFirst Lit software (Mattson Corp.) for data acquisition and handling. The spectra were taken from lightly loaded ( $<1 \mathrm{wt} \%) \mathrm{KBr}$-supported disks of test samples at $4000-400 \mathrm{~cm}^{-1}$, by averaging 20 scans at the resolution of $4 \mathrm{~cm}^{-1}$. Scanning electron microscopy (SEM) was performed with Thermo Fischer Quanta FEG250 scanning electron microscope (Switzerland) at $30 \mathrm{kV}$. Test samples were sputter coated with ca. 2-nm thick gold film 
before examination, by means of a Balzers sputter coater (Liechtenstein). Energy dispersive X-ray (EDX) analysis was done using an Oxford-Instruments (High Wycombe, United Kingdom) EDX system. It is worth noting, that (i) test samples characterized were pre-ground and passed through a $\leq 250$ mesh Sieve, and (ii) equipment used for TG/DTA, XRD and IR analysis were pre-calibrated versus $\mathrm{CaCO}_{3}$ thermal decomposition, Si single crystal, and polyethylene standard film, respectively.

\section{Results and Discussion}

\section{CKD composition and particle morphology}

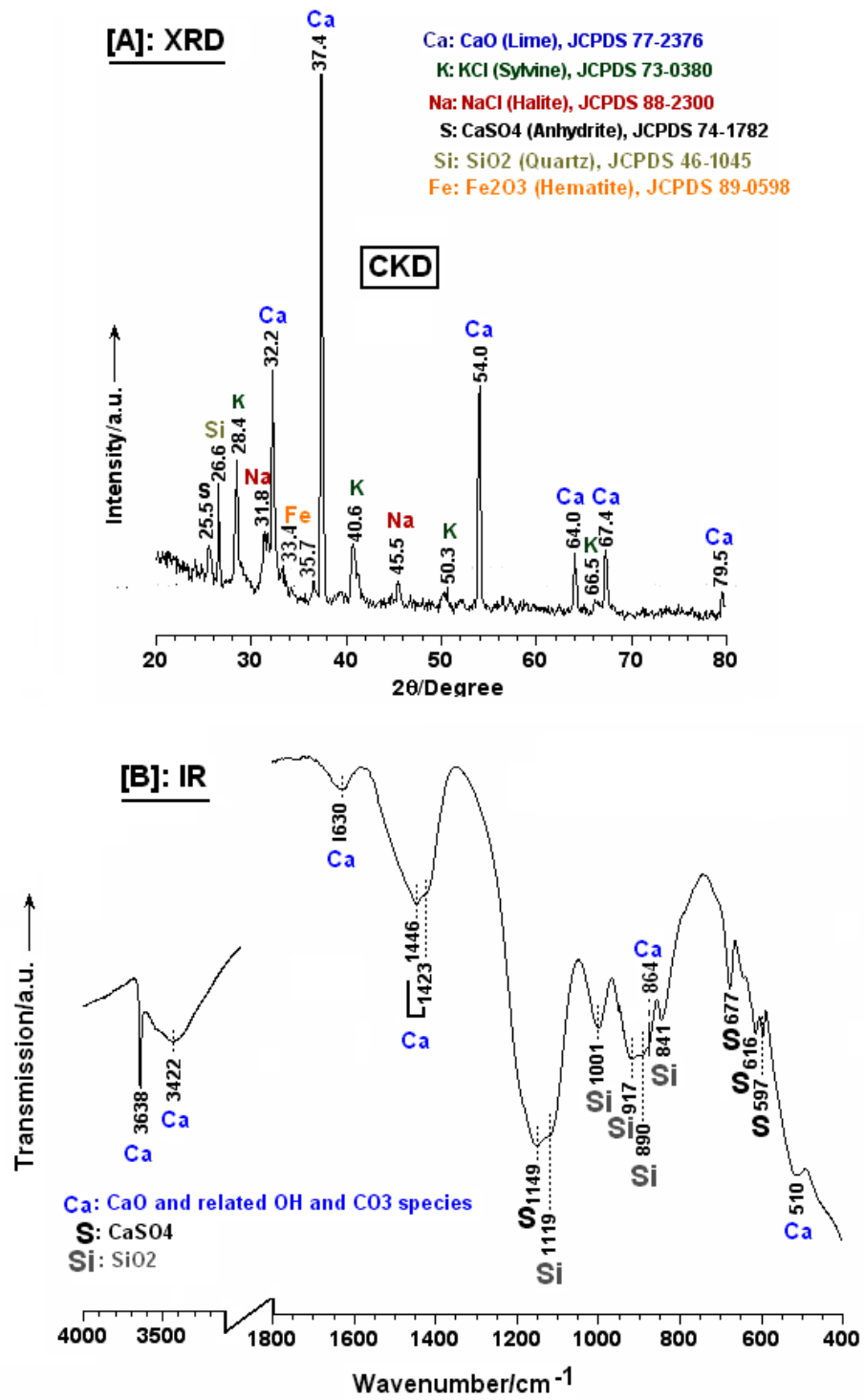

\section{[C]: TGA/DTA}

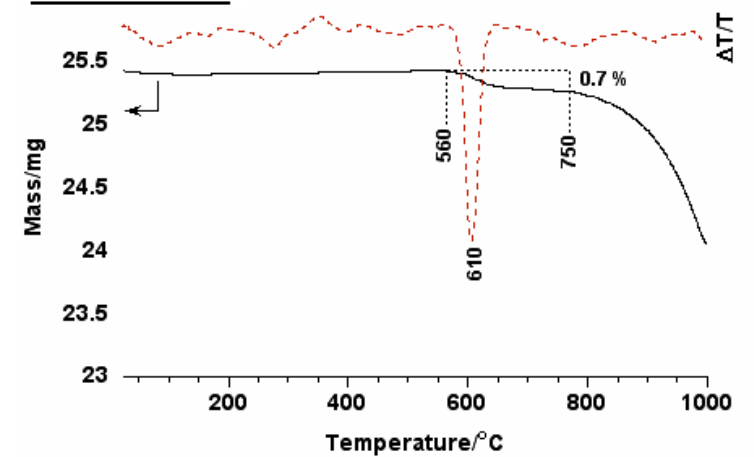

Figure 1: (A) XRD diffractogram; (B) IR spectrum; and (C) TGA/DTA curves obtained for the as-obtained CKD 


\begin{tabular}{|c|c|c|c|c|}
\hline $\begin{array}{l}\text { Composition } \\
/ \pm 0.02 \text { mass \%* }\end{array}$ & \multicolumn{3}{|c|}{ Kiln } & \multirow{2}{*}{ Raw materials } \\
\hline \multirow{2}{*}{$\begin{array}{c}\mathrm{CaO}(50.25), \mathrm{SiO}_{2}(14.66), \mathrm{K}_{2} \mathrm{O}(6.64) \\
\mathrm{SO}_{3}(5.89), \mathrm{Al}_{2} \mathrm{O}_{3}(4.51), \mathrm{Na}_{2} \mathrm{O}(3.30) \\
\mathrm{Fe}_{2} \mathrm{O}_{3}(2.90), \mathrm{MgO}(0.99), \mathrm{Cl}(7.69) \\
\mathrm{LOI} @ 975^{\circ} \mathrm{C}(4.03)\end{array}$} & Type & Process & Temp. $/{ }^{\circ} \mathrm{C}$ & \\
\hline & Short & Dry ${ }^{\star *}$ & $1450^{* * *}$ & $\begin{array}{l}\text { Limestone, clay, } \\
\text { sand, iron ore }\end{array}$ \\
\hline
\end{tabular}

${ }^{\star}$ On-site XRF-determined using a model ARL 9900 Thermo-Fischerspectrometer (Switzerland). XRF calibration was undertaken automatically by a built-in SUS system and 8 standard materials. Results obtained are the average of triplicate measurements.

${ }_{* *}$ With in-line pre-calciner.

${ }_{* * *}^{*}$ Fueled by heavy oil and coal.

Table 1: Provided CKD composition, kiln type and conditions, and raw materials used in the clinker manufacturing

XRD, IR and TGA/DTA results obtained for CKD are exhibited in Figure 1. Matching the diffraction peaks monitored in the XRD diffractogram (Figure 1A) with standard diffraction data [23] revealed that crystalline domains of CKD are majored by $\mathrm{CaO}$ (Lime), and minored by $\mathrm{SiO}_{2}$ (Quartz), $\mathrm{KCl}$ (Sylvine), $\mathrm{CaSO}_{4}$ (Anhydrite), $\mathrm{NaCl}$ (Halite) and $\mathrm{Fe}_{2} \mathrm{O}_{3}$ (Hematite). According to Peethamparan et al. [14], such a crystalline phase composition is typical for CKD released during cement clinker manufacturing under the processing conditions set out in Table 1. Consistently, the corresponding IR spectrum (Figure 1B) monitors absorptions of S-O bond vibrations (at 1149, 677, 616 and $597 \mathrm{~cm}^{-1}$ ) for the $\mathrm{CaSO}_{4}$ [24], and Si-O bond vibrations (at 1119, 1001,917 and $890 \mathrm{~cm}^{-1}$ ) for the $\mathrm{SiO}_{2}$ [24]. It monitors, moreover, absorptions at 3638, 3422, 1630, 1446, 1423, 864 and $510 \mathrm{~cm}^{-1}$, which are frequently encountered in IR spectra taken from partially hydrated and carbonated $\mathrm{CaO}$ [25]. This is in the sense that the former three absorptions (at 3638,3422 and $1630 \mathrm{~cm}^{-1}$ ) are due to $v / \delta \mathrm{OH}$ vibrations arising from hydrated species of $\mathrm{CaO}$, i.e. $\mathrm{Ca}(\mathrm{OH})_{2}$ $[24,25]$. Whereas, the absorptions at 1446,1423 and $864 \mathrm{~cm}^{-1}$ are assignable to $v / \delta \mathrm{CO}_{3}$ vibrations arising from carbonated species of $\mathrm{CaO}$, i.e. $\mathrm{CaCO}_{3}[24,25]$. Partial hydration and carbonation of $\mathrm{CaO}$ are influenced by the known strong tendency of $\mathrm{CaO}$ towards adsorption/absorption of ambient $\mathrm{H}_{2} \mathrm{O}$ and $\mathrm{CO}_{2}$ molecules yielding $\mathrm{Ca}(\mathrm{OH})_{2}$ and $\mathrm{CaCO}_{3}$ impurity species in the $\mathrm{CKD}$. The absence of XRD indications (Figure 1A) for these impurity species may be due to their scarce presence and/or non-crystallinity. It is worth noting, that the XRD-observed chlorides of $\mathrm{K}$ and $\mathrm{Na}$ (Figure $1 \mathrm{~A}$ ) are not accessible to IR spectroscopy over the frequency range scanned [24].

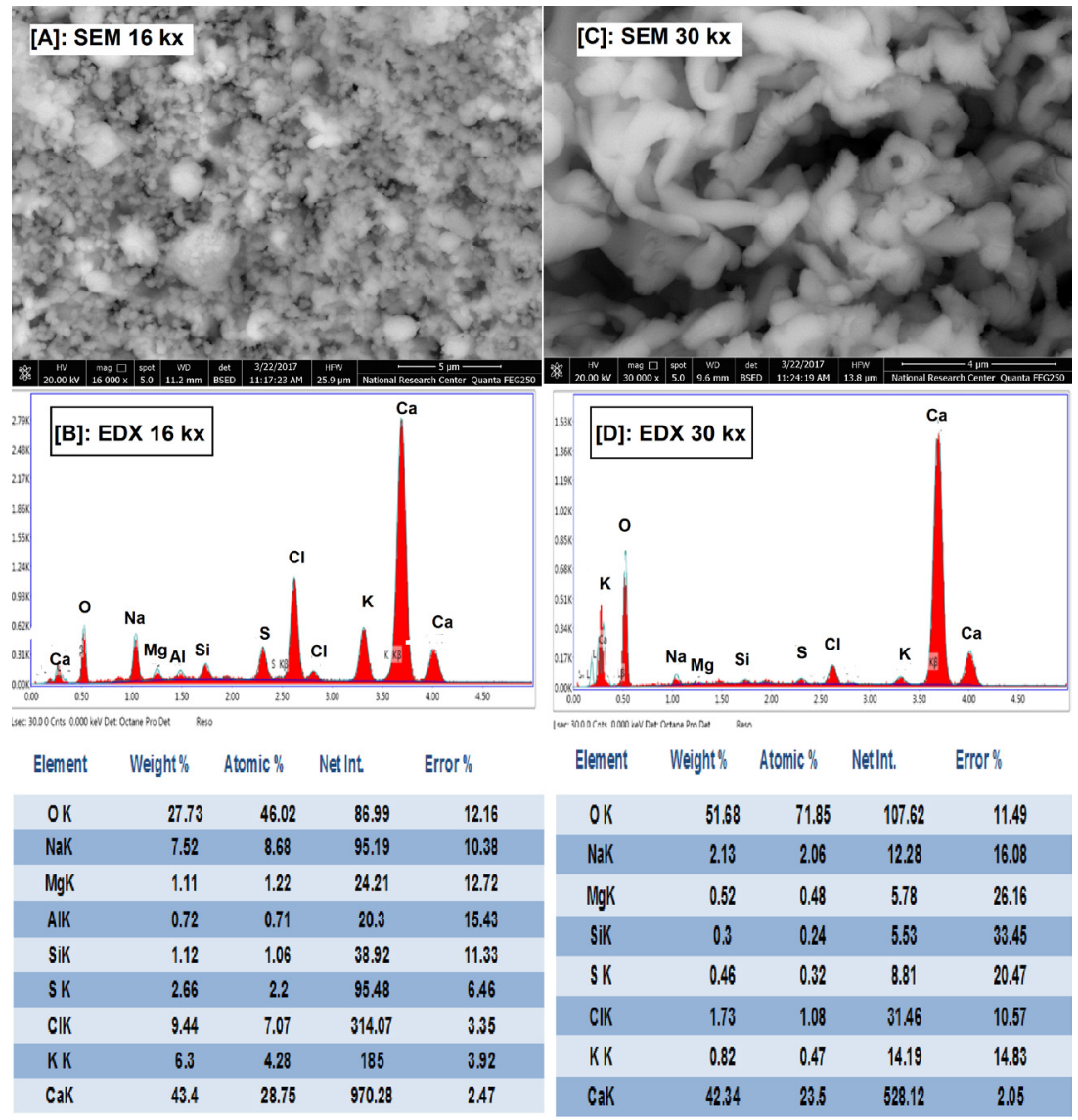

Figure 2: SEM images (A and C) and EDX spectra (B and D) obtained for CKD. Tables underneath set out analytical results derived from the EDX spectrum above each

TGA and DTA curves obtained for CKD (Figure 1C) indicate that it is thermally stable to heating up to $560{ }^{\circ} \mathrm{C}$, but at higher temperatures it suffers a minor mass loss (ca. $0.7 \%$ ) via an endothermic decomposition process maximized at $610{ }^{\circ} \mathrm{C}$, and a larger 
mass loss $>750{ }^{\circ} \mathrm{C}$, which is shown to extend beyond the highest temperature scanned $\left(1000{ }^{\circ} \mathrm{C}\right)$. On-site LOI determination at 975 ${ }^{\circ} \mathrm{C}$ brought about a value of $4.03 \%$ (Table 1), which may corroborate ascribing the TGA-observed high-temperature mass loss to a minor decomposition process. The fact that $\mathrm{Ca}(\mathrm{OH})_{2}$ has been reportedly found [26] to decompose into $\mathrm{CaO}$ and $\mathrm{H}_{2} \mathrm{O}$ near $600{ }^{\circ} \mathrm{C}$, but $\mathrm{CaCO}_{3}$ decomposes $>750{ }^{\circ} \mathrm{C}$ [25], may consider the observed mass loss maximized at $610{ }^{\circ} \mathrm{C}$ to be due to the decomposition of the $\mathrm{Ca}(\mathrm{OH})_{2}$ minority species, whereas the larger mass loss at $>750{ }^{\circ} \mathrm{C}$ to undertake that of the $\mathrm{CaCO}_{3}$ species. It is worth noting, however, that contribution of decomposition and/or sublimation of other constituents of CKD (e.g., sulfate and/or chlorides) to the high-temperature mass loss cannot be excluded with certainty. It is worth admitting, that the TGA-observed non-isothermal mass losses were the thrust behind examining consequences of isothermal heat treatments of $\mathrm{CKD}$ at $500-1000{ }^{\circ} \mathrm{C}$ (vide infra).

SEM image (16 kx) taken from CKD is shown (Figure $2 \mathrm{~A}$ ) to visualize loose globular particles of sizes $\leq 2 \mu \mathrm{m}$, as well as particle aggregates of larger sizes (up to $6 \mu \mathrm{m}$ ). The corresponding EDX spectrum (Figure $2 \mathrm{~B}$ ) is shown to detect most of the elements expected from Table 1. Analytical data derived therefrom (set out in the table inset underneath) convey relative elemental proportions in line with the XRF-determined proportions (Table 1). EDX probing across the sample could identify CaO-rich particles (Figure 1D and the table underneath), whose SEM image (Figure 1C) finds them to assume warm-like shapes of preferential growth direction, but of non-preferential orientation. Furthermore, these $\mathrm{CaO}$-rich particles are shown to be slightly coalescent and to assume varied lengths in the range 336-678 $\mathrm{nm}$ (Figure S1, in online Supplementary Material).

\section{Consequences of heat treatment}

\section{CS: Ca2SiO4 (Larnite), JCPDS 77-0409}

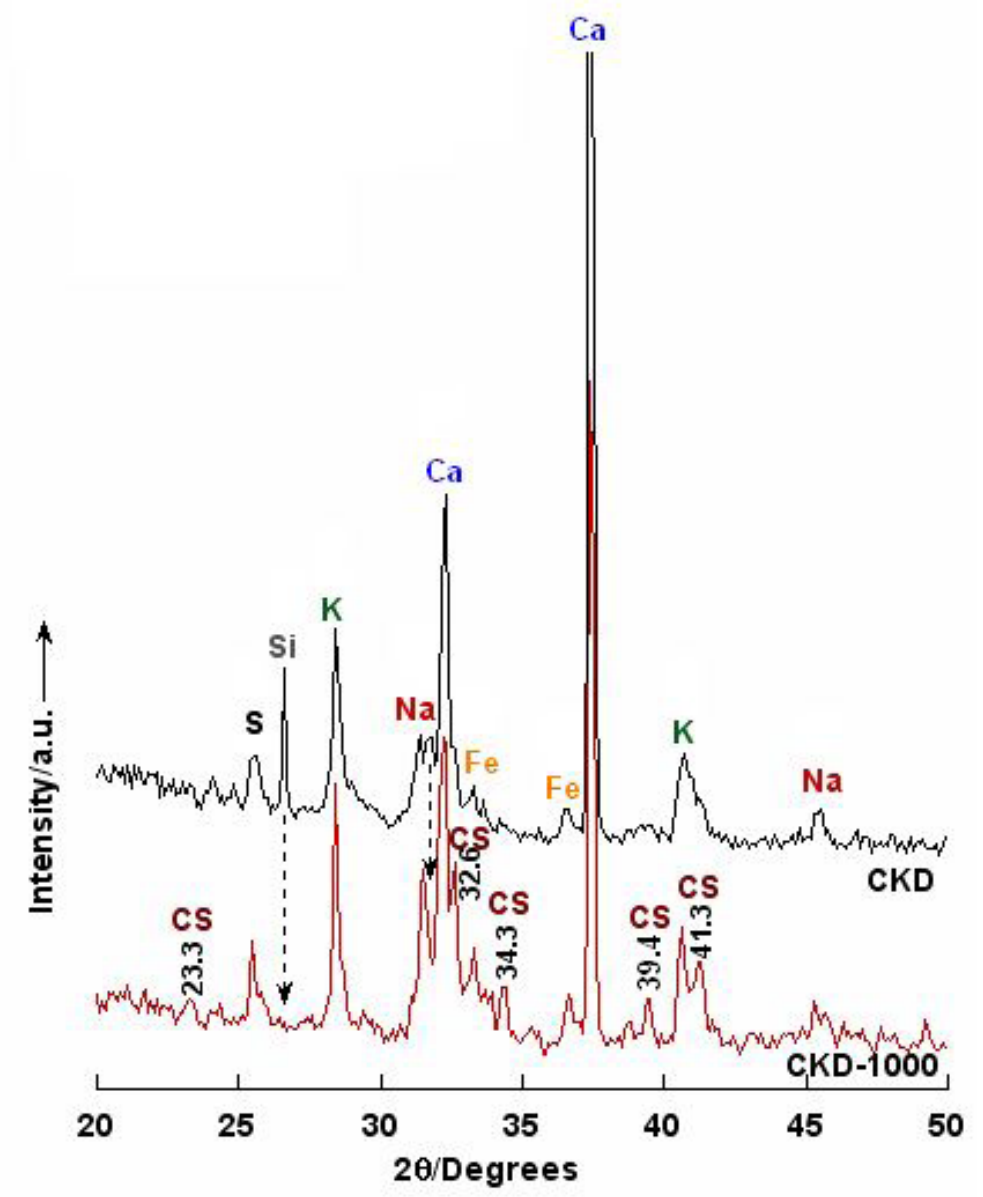

Figure 3: XRD diffractograms obtained for $\mathrm{CKD}$ and its calcination product at $1000^{\circ} \mathrm{C}$ for $1 \mathrm{~h}(\mathrm{CKD}-1000)$

Compositional consequences of calcining CKD at 500, 650 and $1000{ }^{\circ} \mathrm{C}$ (for $1 \mathrm{~h}$ ) were identified by means of the XRD powder diffractograms compared in Figure S2, and IR spectra stacked in Figure S3. Figure S2 shows that most of the diffraction peaks given rise by $\mathrm{CKD}$ are maintained in the diffractograms of the calcination products, except for a gradual weakening of the diagnosing peak ( $\mathrm{Si}$-labeled at $2 \theta=26.7^{\circ}$ ) of $\mathrm{SiO}_{2}$ with increasing temperature till complete disappearance in the diffractogram of CKD-1000. In contrast, the diagnosing peak (S-labeled at $2 \theta=25.6^{\circ}$ ) of $\mathrm{CaSO}_{4}$, though is shown to have varied intensities, remained visible in the diffractogram of CKD-1000. On the other hand, three weak, but distinct, peaks emerged (CS-labeled at $2 \theta=32.6,34.3$ and $\left.41.3^{\circ}\right)$ in 
the diffractogram of CKD-1000. According to the standard data filed in JCPDS file No. 77-0409 [23], these are the three strongest peaks of $\mathrm{Ca}_{2} \mathrm{SiO}_{4}$ (Larnite). Formation of Larnite is, most likely, due to a solid state reaction between $\mathrm{SiO}_{2}$ and $\mathrm{CaO}$ activated at high temperature ( $\mathrm{ca} .1000^{\circ} \mathrm{C}$ ). This may be justified by the observed disappearance of the diagnostic diffraction peak of $\mathrm{SiO}_{2}$ as well as the relative weakening of $\mathrm{CaO}$ (Lime) diffraction peaks (Ca-labeled, Figure S2) particularly in the diffractogram of CKD-1000. It is worth noting, that peaks due to $\mathrm{KCl}$ (Sylvine) and $\mathrm{NaCl}$ (Halite) are still clearly observed in the diffractogram of CKD-1000. In order to better resolve and highlight the described ultimate changes in the mineralogical composition as a consequence of heating, close-up diffractograms of CKD and CKD-1000 are compared in Figure 3.

IR spectra taken from CKD and its calcination products, shown in Figure S3, do not only sustain the XRD-observed compositional consequences of heating CKD, but also reveal changes occurred in its non-crystalline species. This is manifested in (i) the significant weakening and sharpening of the $\mathrm{SiO}_{2}$ (Quartz) absorptions at 1119, 1001, 917, 890 and $841 \mathrm{~cm}^{-1}$ due to its conversion into Ca $\mathrm{SiO}_{4}$ (Larnite) [25], (ii) the almost complete elimination of the absorptions assignable to $\mathrm{Ca}(\mathrm{OH})_{2}$ and $\mathrm{CaCO}_{3}$ (at 3638, 3422, 1630, 1446, 1423 and $864 \mathrm{~cm}^{-1}$ ) [24,25], and (iii) the weakening of diagnostic absorptions of $\mathrm{CaSO}_{4}$ (Anhydrite) at 1149, 677, 616 and 597 $\mathrm{cm}^{-1}$. The comparison held in Figure S3 reveals, moreover, that the $v \mathrm{OH}$-absorptions (at 3638 and $3422 \mathrm{~cm}^{-1}$ ), i.e. those diagnostic of the presence of non-crystalline $\mathrm{Ca}(\mathrm{OH})_{2}$ species, are significantly weakened in the spectrum of CKD-650, whereas those of $\mathrm{CaCO}_{3}$ and $\mathrm{CaSO}_{4}$ are shown, respectively, to be eliminated and weakened but only in the spectrum of CKD-1000. These results may support that the TGA-monitored $0.7 \%$ mass loss at $560-650{ }^{\circ} \mathrm{C}$ (Figure $1 \mathrm{C}$ ) is confined to the decomposition of $\mathrm{Ca}(\mathrm{OH})_{2}$ $[24,25]$, whereas the larger mass loss (ca. $4 \%$, Table 1 ) observed at $>750^{\circ} \mathrm{C}$ involves the complete decomposition of $\mathrm{CaCO}_{3}$ species as well as a partial elimination of $\mathrm{CaSO}_{4}$.

Exploring morphological consequences of heating was sought by SEM examination of CKD-1000. Image obtained and corresponding EDX microanalysis results are given in Figure S4. The SEM image (Figure S4A) visualizes some remarkable morphological modifications: (i) overall particle thickening and size increase, (ii) formation of particle agglomerates with signs of frozen melts, which are more visible in Figure S4B, and (iii) formation of rod-like particles. The particle size increase and agglomeration are due, expectedly, to enhanced mass transfer at such a high temperature of calcination $\left(1000{ }^{\circ} \mathrm{C}\right)$. The melts are most likely of chlorides of $\mathrm{K}$ and $\mathrm{Na}$, which are still there as evidenced in the EDX analytical results (Figure S4C and D). On the other hand, the rod-like particles are presumably formed at the expense of the original warm-like CaO-rich particles of CKD (Figure 2C). This modification might have been influenced as a result of the formation of $\mathrm{Ca}_{2} \mathrm{SiO}_{4}$. Compatibly, the EDX analysis results (Figure S4C) brought about much higher proportions for $\mathrm{Ca}(29.75 \%)$ and $\mathrm{Si}(8.72 \%)$ than for the other metal components probed $(\leq 4.03 \%)$.

Summing up, the test $\mathrm{CKD}$ has been found largely stable to heat treatment at $500{ }^{\circ} \mathrm{C}$. Upon increasing the temperature up to 650 ${ }^{\circ} \mathrm{C}$, it was freed from minority $\mathrm{Ca}(\mathrm{OH})_{2}$ species via thermal decomposition. At $1000{ }^{\circ} \mathrm{C}$, CKD was freed further from minority $\mathrm{CaCO}_{3}$ species via thermal decomposition, and the $\mathrm{SiO}_{2}$ (Quartz) content of CKD was activated for a solid state reaction with

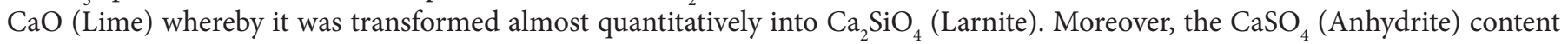
was only partially reduced in magnitude, whereas the chlorides of $\mathrm{Na}$ and $\mathrm{K}$ commenced to melt but without significant mass loss. Hence, the heat treatment applied could not free CKD from the chloride and sulfate contents, whose presence is known to hamper CKD reuse as a raw material in the clinker production [7].

\section{Consequences of water treatment}

Irrespective of the water treatment mode applied (i.e., long-term (LT) or short-term (ST)), and whether the treated material is CKD or its calcination product at $1000{ }^{\circ} \mathrm{C}$ (CKD-1000), the yield is two-fold: (i) a crystalline leachate (L), and (ii) a pulverized solid residue $(\mathrm{R}))$.

\section{Long-term processing}

The solid residues: XRD diffractograms obtained for the solid residues of long-term water-treated CKD (i.e., CKD(LT/R)) and CKD-1000 (i.e., CKD-1000(LT/R)) are compared to those obtained for the untreated materials in Figure 4. The comparison reveals that the diffractogram of CKD (LT/R) is almost completely void of diagnostic peaks of $\mathrm{CaO}, \mathrm{SiO}_{2}, \mathrm{Fe}_{2} \mathrm{O}_{3}, \mathrm{KCl}$ and NaCl. It declares, moreover, a weakening of the diagnostic (S-labeled) peak of $\mathrm{CaSO}_{4}$, and the emergence of six new (CC-labeled) peaks (at 20=29.4, 36.0, 39.5, 43.2, 47.6 and 48.50) due to formation of $\mathrm{CaCO}_{3}$ (Calcite, JCPDS 88-1812) [23]. On the other hand, the diffractogram obtained for CKD-1000(LT/R) shows not only the disappearance of peaks of $\mathrm{Fe}_{2} \mathrm{O}_{3}, \mathrm{KCl}$ and $\mathrm{NaCl}$, but also weakening of the peaks of $\mathrm{Ca}_{2} \mathrm{SiO}_{4}$ due, most likely, to its gelation into calcium silicate hydrate $(\mathrm{CSH})$ and non-crystalline $\mathrm{Ca}(\mathrm{OH})_{2}$ species [27]. It also monitors peaks of $\mathrm{CaCO}_{3}$ at detectably lower intensities than those monitored in $\mathrm{CKD}(\mathrm{LT} / \mathrm{R})$, and $\mathrm{CaSO}_{4}$. Consistent results are communicated in the corresponding IR spectra compared in Figure S5. These results are in line with the facts that upon hydrolysis (i) $\mathrm{CaO}$ is transformed into $\mathrm{Ca}(\mathrm{OH})_{2}$ (Portlandite), which, in turn, absorbs ambient $\mathrm{CO}_{2}$ to convert into CaCO$(\mathrm{Calcite})$ [27], (ii) $\mathrm{Ca}_{2} \mathrm{SiO}_{4}$ (Larnite) is readily transformed into $\mathrm{Ca}(\mathrm{OH})_{2}$ (and eventually to $\mathrm{CaCO}_{3}$ ) and $\mathrm{CSH}_{\text {gel }}[14,27]$, (iii) $\mathrm{KCl}$ and $\mathrm{NaCl}$ are readily dissolved in the aqueous medium, and (iv) $\beta-\mathrm{CaSO}_{4}(\beta$-Anhydrite), a high-temperature transformation product of CaSO is sparingly soluble in water [27], However, the disappearance of the XRD diagnostic peak (at $\left.\theta=26.6^{\circ}\right)$ of $\mathrm{SiO}_{2}(\mathrm{Quartz})$ in the diffractogram of CKD(LT/R) (Figure 4) is due, presumably, to its conversion into non-crystalline CSH species [27]. 
CC: CaCO3 (Calcite), JCPDS 88-1812

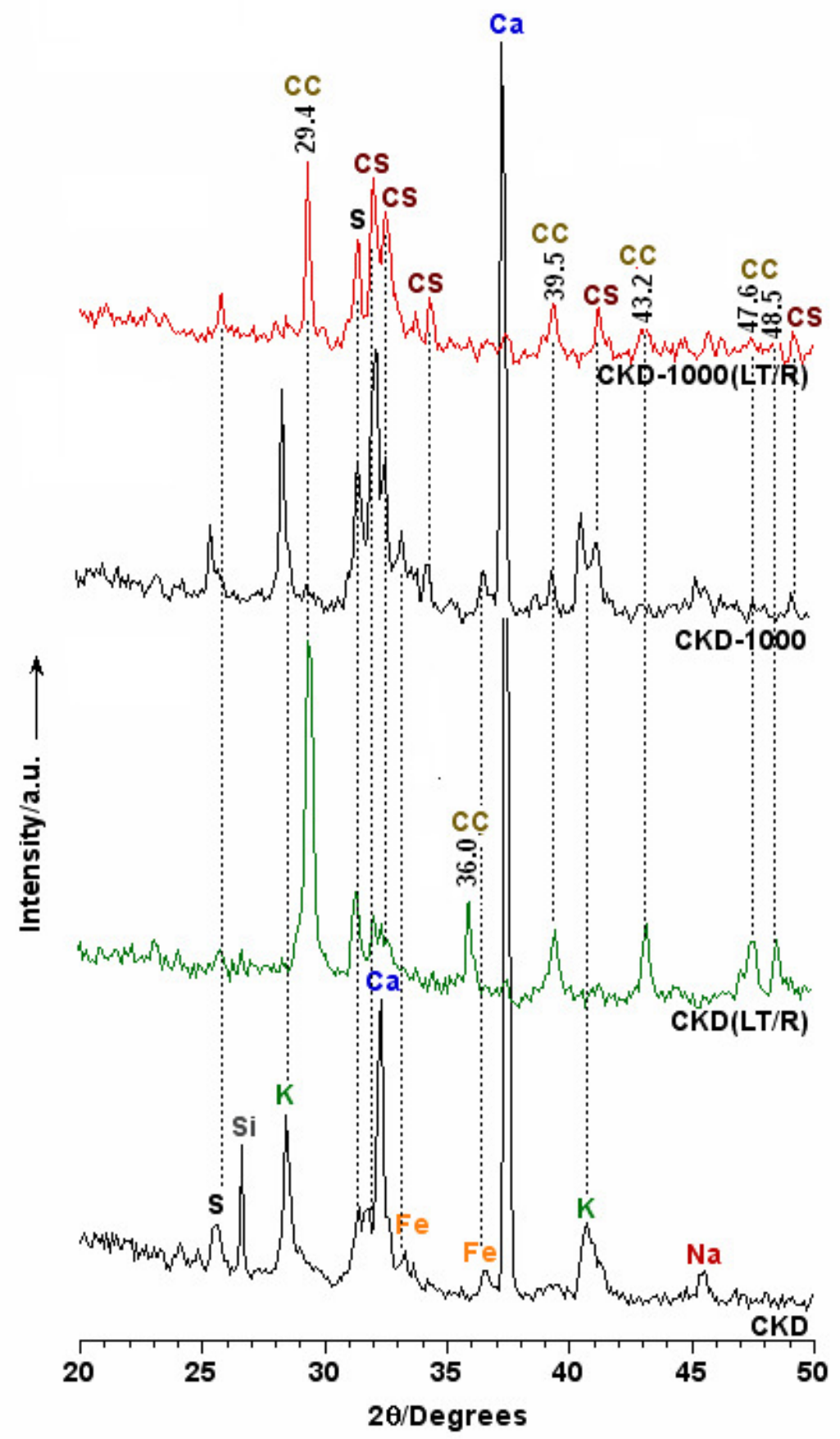

Figure 4: XRD diffractograms obtained for long-term water treatment solid residues of CKD (i.e., CKD(LT/R)) and CKD-1000 (i.e., CKD-1000(LT/R)). The diffractograms of the untreated CKD and CKD-1000 are inset for comparison purposes

Morphological consequences of the long-term water treatment of CKD were examined by SEM and EDX microanalysis. SEM image obtained for CKD (LT/R) (Figure 5) resolves three discernible particle morphologies; namely, A-labeled rod-like particles, B-labeled sponge-like particles, and C-labeled cubic-like particles. Neither of these particle morphologies is observable in the SEM images (Figure 2) obtained for CKD before exposure to the water treatment, which are shown to be dominated by CaO-rich warm-like particles, plus loose and aggregated globular particles (Figure 2A). Therefore, it is plausible to relate these new particle morphologies to water-treatment influenced changes to the initial CKD composition, i.e. the formation of $\mathrm{CaCO}_{3}$ at the expense of $\mathrm{CaO}$, and the conversion of quartz-SiO into non-crystalline $\mathrm{CSH}$ species. EDX microanalysis results obtained for the A-labeled rod-like particles, set out in Table S1, reveal that they are $\mathrm{Ca}(17.46 \%)$ and $\mathrm{C}(16.87 \%)$ enriched. Hence, the rod-like particles are most probably due to $\mathrm{CaCO}_{3}$. EDX results obtained for the B-labeled sponge-like particles (Table S2) reveal further Ca (23.26 $\%)$ and C (21.37 \%) enrichment, as well as Si (3.76\%) enrichment, which may help relating the sponge-like morphology to noncrystalline domains dwelling CSH species. In contrast, Table S3 indicates that the C-labeled cubic-like particles are distinct by the highest proportion of $\mathrm{Fe}(28.17 \%)$, which may help suggesting that they contain non-crystalline $\mathrm{FeO}(\mathrm{OH}) \mathrm{x}$ species. 


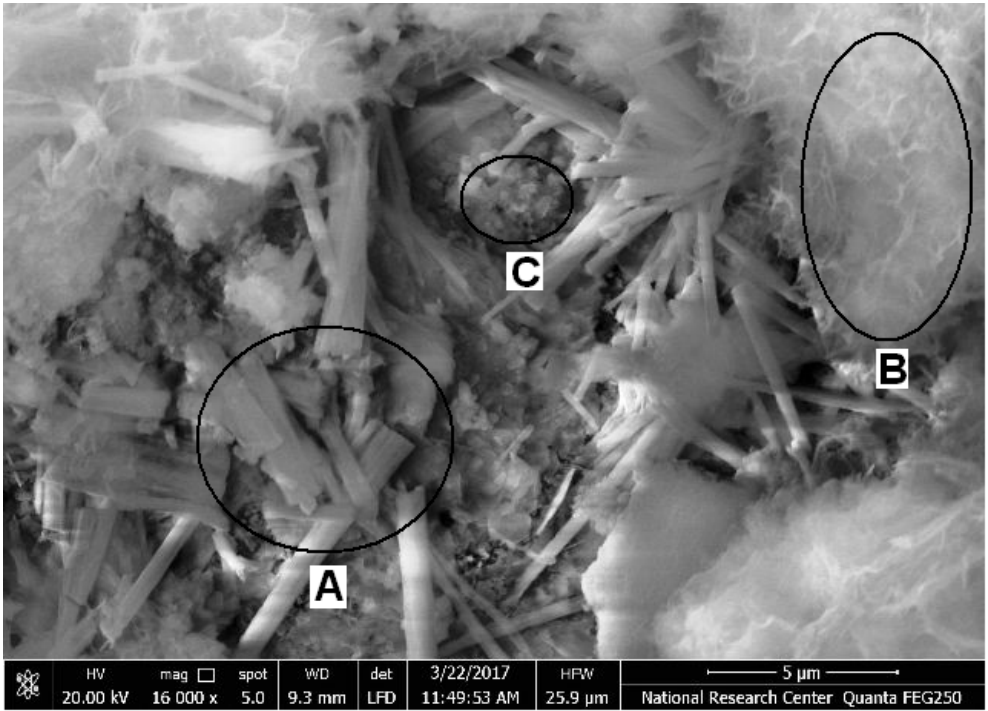

Figure 5: SEM image obtained for CKD(LT/R). Encircled are the different morphologies observed: (A) rod-like particles; (B) sponge-like particles; and (C) cubic-like particles. Corresponding EDAX analysis results are set out in Tables S1, S2 and S3, respectively

The leachate crystals: It is obvious from the XRD diffractogram exhibited in Figure 6, that the CKD leachate (i.e., CKD(LT/L) is composed of crystalline salts of $\mathrm{CaCO}_{3}$ (Calcite), $\mathrm{KCl}$ (Sylvine) and $\mathrm{NaCl}$ (Hallite). The corresponding IR spectrum is shown (Figure 7) to be dominated by diagnostic absorptions (at 2518, 1800, 1430, 869 and $713 \mathrm{~cm}^{-1}$ ) of $\mathrm{CaCO}_{3}$ (Calcite) [24], since $\mathrm{KCl}$ and $\mathrm{NaCl}$ bond vibrations are observable only $<400 \mathrm{~cm}^{-1}$ [24]. The broad absorption centered around $3465 \mathrm{~cm}^{-1}$ is indicative of the presence of hydrogen-bonded $\mathrm{OH}$-groups of retained water molecules. Whereas the shoulder at $1163 \mathrm{~cm}^{-1}$ and the tiny, but distinct, peak at $605 \mathrm{~cm}^{-1}$, which are assignable to S-O vibrations [24], may imply the presence of non-crystalline calcium sulfate species. The failure of EDX spectroscopy to detect $\mathrm{Na}, \mathrm{K}$ and $\mathrm{Cl}$ in the solid residue $\mathrm{CKD}(\mathrm{LT} / \mathrm{R}$ ) (Tables S1-S3) may evidence their almost complete leaching out under the long-term water treatment conditions applied. The subsequent slow natural evaporation of the water at RT (completed in 14 days) must have furnished the necessary conditions for crystal growth of $\mathrm{KCl}$ and $\mathrm{NaCl}$. On the other hand, the presence of Calcite large crystals in the leachate $(\mathrm{CKD}(\mathrm{LT} / \mathrm{L}))$, and microcrystallites in the solid residue CKD(LT/R) (Figure 4), should have occurred via one-and-the-same formation course: $\mathrm{CaO}(\mathrm{s})+\mathrm{H}_{2} \mathrm{O}(\mathrm{l})=\mathrm{Ca}(\mathrm{OH})_{2}+\operatorname{ambient} \mathrm{CO}_{2}(\mathrm{~g})=\mathrm{CaCO}_{3}(\mathrm{~s})+\mathrm{H}_{2} \mathrm{O}(\mathrm{l})$ [27]. Unlike the complete leaching out of the elements of $\mathrm{KCl}$ and $\mathrm{NaCl}$ from $\mathrm{CKD}$, the much larger proportion of $\mathrm{CaO}$ has rendered its leaching out incomplete under the water treatment conditions applied. It is worth mentioning, that subjecting CKD-1000 to the same long-term water treatment resulted in leachate crystals of Calcite only (Figure S6). The corresponding SEM and EDX analysis results (Figure S7) disclose the presence in the leachate (CKD-1000(LT/L) of detectable amounts of non-crystalline $\mathrm{KCl}$ and $\mathrm{NaCl}$ species. This may imply that their melting in CKD-1000 (Figure S4) may have rendered them sparingly soluble in water, thus rendering their soluble concentrations far less than the necessary saturation level for crystallization.

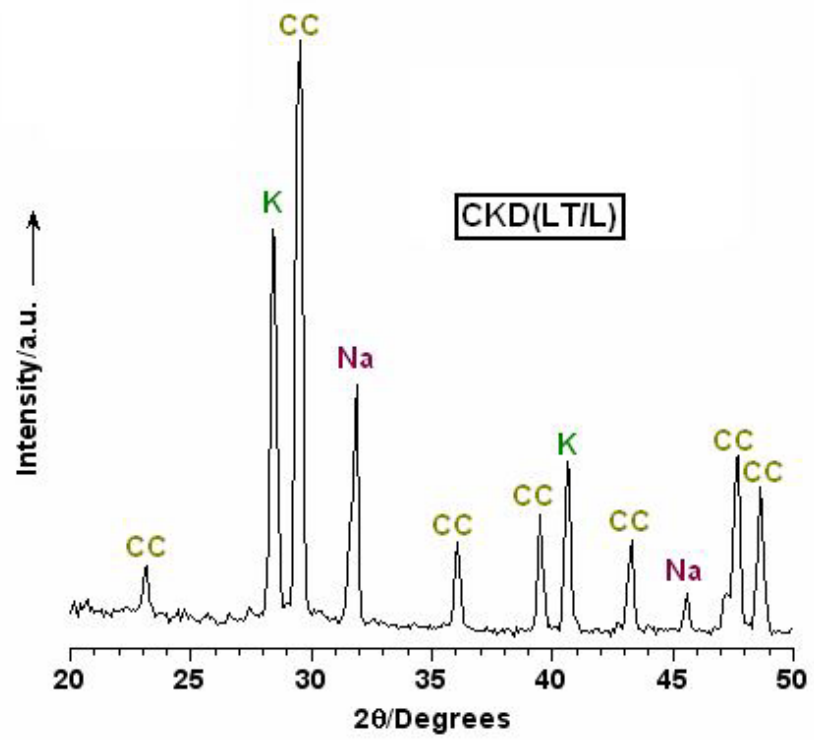

Figure 6: X-ray diffractogram obtained for the leachate of CKD after long-term water treatment, i.e. CKD(LT/L) 


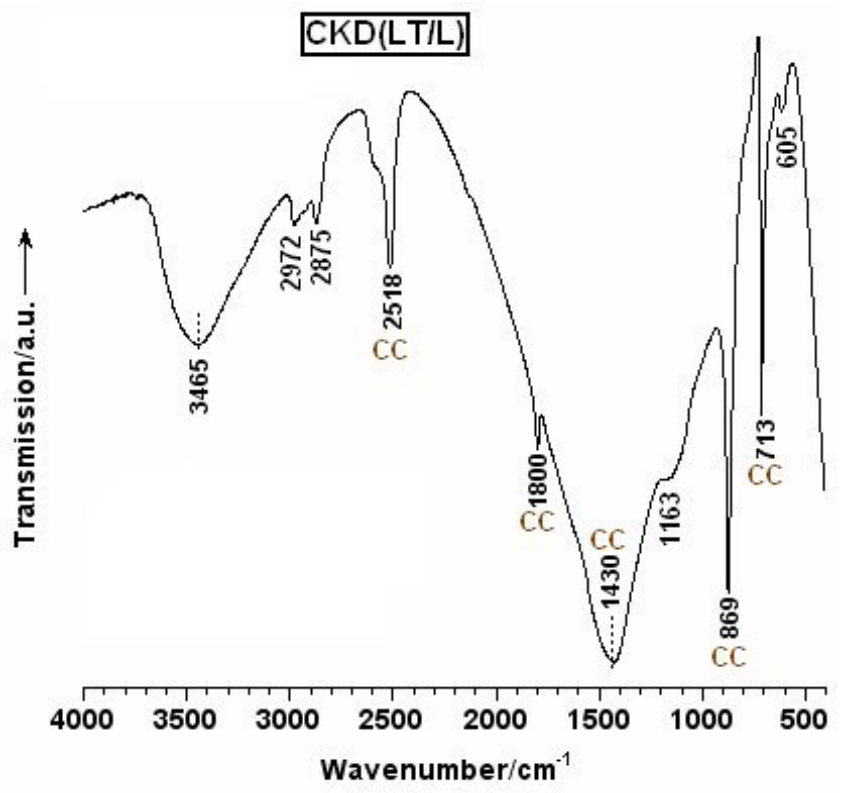

Figure 7: IR spectrum obtained for CKD(LT/L)

\section{Short-term processing}

Shortening the soaking period of CKD particles in water $(1 \mathrm{~g} / 40 \mathrm{~mL})$ to $15 \mathrm{~min}$ (instead of 14 days), the dried filtrate (CKD(ST/L)) and soild residue $(\mathrm{CKD}(\mathrm{ST} / \mathrm{R})$ exhibited the XRD diffractograms compared in Figure S8. The comparison reveals that the leachate crystals formed were of $\mathrm{CaCO}_{3}$ (Calcite), $\mathrm{NaCl}$ (Hallite) and $\mathrm{KCl}$ (Sylvine), as well as $\mathrm{CaSO}_{4} \cdot 2 \mathrm{H}_{2} \mathrm{O}$ (Gypsum, JCPDS 06-0047)) [23] . On the other hand, the solid residue is shown to be still majored by microcrystallites of $\mathrm{CaO}$ (Lime), but minored by microcrystallites of $\mathrm{CaCO}_{3}$ (Calcite). In contrast, none of the diffraction peaks of $\mathrm{NaCl}$ and $\mathrm{KCl}$ are monitored in the XRD diffractogram of the solid residue CKD(ST/R) (Figure S8). SEM and EDX analysis results (Figure S9) obtained for CKD(ST/R) resolve, according to Peethmparan et al. [14], the co-existence of non-crystalline aggregates of $\mathrm{Ca}(\mathrm{OH})_{2}$ and $\mathrm{CSH}$ species. Accordingly, the short soaking period of CKD particles in water facilitates leaching out most of the $\mathrm{KCl}, \mathrm{NaCl}$ and $\mathrm{CaSO}_{4}$ contents of $\mathrm{CKD}$, and help leaching but a small proportion of its initially high content of $\mathrm{CaO}$. These results, together with the detection of non-crystalline $\mathrm{Ca}(\mathrm{OH})_{2}$ in the residue, may suggest that the hydration, and subsequent carbonation, of $\mathrm{CaO}$ are slow processes; hence, their completion require long CKD/water contact time.

\section{Conclusion}

The above presented and discussed results may help drawing the following conclusions, which are further graphically summarized in Figure S10:

1. CKD composition is stable to heating (in air) up to $500^{\circ} \mathrm{C}$. It is freed from minority $\mathrm{Ca}(\mathrm{OH})_{2}$ species via thermal decomposition at $650^{\circ} \mathrm{C}$. At $1000{ }^{\circ} \mathrm{C}$, it is further freed from minority $\mathrm{CaCO}_{3}$ species via thermal decomposition, the $\mathrm{SiO}_{2}(\mathrm{Quartz})$ content is activated for a solid state reaction with $\mathrm{CaO}$ (Lime) whereby it is transformed almost quantitatively into $\mathrm{Ca}_{2} \mathrm{SiO}_{4}\left(\mathrm{Larnite}_{\text {) }}\right.$. Moreover, the $\mathrm{CaSO}_{4}$ (Anhydrite) content was only partially eliminated, whereas the chlorides of $\mathrm{Na}$ and $\mathrm{K}$ commenced to melt but without significant mass loss.

2. Hence, the heat treatment up to $1000{ }^{\circ} \mathrm{C}$ cannot free $\mathrm{CKD}$ from the chloride and sulfate contents, whose presence is known to hamper the CKD reuse as a raw material in the clinker production.

3. The chloride and sulfate contents are, however, leached out almost completely while soaking CKD particles in water ( $1 \mathrm{~g} / 40 \mathrm{~mL})$ with stirring for as short as $15 \mathrm{~min}$. Meanwhile, the $\mathrm{CaO}$ content is partially hydrated into $\mathrm{Ca}(\mathrm{OH})_{2}$, which is carbonated (via acid-base interaction with ambient $\mathrm{CO}_{2}$ molecules) to yield $\mathrm{CaCO}_{3}$ both in the aqueous and solid residue. Moreover, the Quartz$\mathrm{SiO}_{2}$ and Hematite- $\mathrm{Fe}_{2} \mathrm{O}_{3}$ contents are hydrolyzed into non-crystalline species.

4. The hydration and carbonation processes of the $\mathrm{CaO}$ content are slow and, therefore, require a longer $\mathrm{CKD} /$ water contact time to be completed.

5. The slow evaporation of water (under ambient conditions) from the aqueous leachate results in the formation of visibly large flake-like aggregates of crystals of $\mathrm{CaCO}_{3}$ (Calcite), $\mathrm{CaSO}_{4} \cdot 2 \mathrm{H}_{2} \mathrm{O}$ (Gypsum), $\mathrm{KCl}$ (Sylvine) and $\mathrm{NaCl}$ (Halite).

6. Hence, a 15 -min stirring of CKD in water $(1 \mathrm{~g} / 40 \mathrm{~mL})$ is sufficient to bring down its chloride and sulfate salt content to $<6 \%$, which renders possible the reusing of $\mathrm{CKD}$ as a raw material in the clinker manufacturing, thereby minimizing its environmental hazards. 


\section{Conflict of interest}

We declare that we do not have any commercial or associative conflict of interest in connection with the present work.

\section{Acknowledgment}

We acknowledge with appreciation a donation from the Alexander von Humboldt-Foundation (Bonn) that made possible the purchase of the FT-IR spectrophotometer.

\section{Supplementary Material}

\section{References}

1. Zhao Y, Zhan J, Liu G, Zheng M, Jin R, et al. (2017) Evaluation of dioxins and dioxin-like compounds from a cement plant using carbide slag from chlor-alkali industry as the major raw material. J Hazard Mater 330: 135-41.

2. Ahmed HY, Othman AM, Mahmoud AA (2006) Effect of using waste cement dust as a mineral filler on the mechanical properties of hot mix asphalt. Ass Univ Bull Environ Res 9: 51-60.

3. Konsta-Gdoutos M, Shah S (2003) Hydration and properties of novel blended cements based on cement kiln dust and blast furnace slag. Cem Concr Res 33: $1269-76$

4. Maslehuddin M, Al-Amoudi OSB, Shameem M, Rahman MK, Ibrahim M (2008) Usage of cement kiln dust in cement products - Research review and preliminary investigations. Constr Build Mater 22: 2369-75.

5. Abdel-Gawwad HA, Khalil KhA (2018) Application of thermal treatment on cement kiln dust and feldspar to create one-part geopolymer cement. Constr Build Mater 187: 231-7.

6. Kunal R, Siddique R, Rajor A (2012) Use of cement kiln dust in cement concrete and its leachate characteristics. Res Conserv Recy 61: 59-68.

7. El-Attar MM, Sadek DM, Salah AM (2017) Recycling of high volumes of cement kiln dust in bricks industry. J Clean Prod 143: 506-15.

8. Maslehuddin M, Al-Amoudi OSB, Rahman MK, Ali M, Barry M (2009) Properties of cement kiln dust concrete. Constr Build Mater 23: 2357-61.

9. Salem WM, Sayed WF, Halawy SA, Elamary RB (2015) Physicochemical and microbiological characterization of cement kiln dust for potential reuse in wastewater treatment. Ecotoxicol Environ Saf 119: 155-61.

10. Abdel-Fattah WI, El-Didamony H (1981) Thermal investigation on electrostatic precipitator kiln dust. Thermochim Acta 51: 297-306.

11. Felekoglu B, Türkel S, Baradan B (2007) Effect of water/cement ratio on the fresh and hardened properties of self-compacting concrete. Build Environ 42: 1795-802.

12. Siddique R (2014) Utilization of industrial by-products in concrete. Proced Eng 95: 335-47.

13. Abdel Aziz EM, Altohamy AK, Towfeek AR (2010) Physical and chemical properties for stabilized sand using cement kiln dust. J Eng Sci Ass Univ 38: 655-69.

14. Peethmparan S, Olek J, Lovell J (2008) Influence of chemical and physical characteristics of cement kiln dusts (CKDs) on their hydration behavior and potential suitability for soil stabilization. Cem Concr Res 38: 803-15.

15. Adaska WS, Taubert DH (2008) Beneficial uses of cement kiln dust. IEEE/PCA $50^{\text {th }}$ Cement Industry Technical Conference, USA.

16. Arulrajah A, Mohammadinia A, D’Amico A, Horpibulsuk S (2017) Cement kiln dust and fly ash blends as an alternative binder for the stabilization of demolition aggregates. Const Build Mater 145: 218-25.

17. Abdel-Gawwad HA, Heikal M, Mohamed MS, Abd El-Aleem S, Hassan HS, et al. (2019) Sustainable disposal of cement kiln dust in the production of cementitious materials. J Cleaner Prod 232: 1218-29.

18. Modarres A, Ramyar H, Ayar P (2015) Effect of cement kiln dust on the low-temperature durability and fatigue life of hot mix asphalt. Cold Regions Sci Technol 110: 59-66.

19. Mackie M, Boilard S, Walsh ME, Lake CB (2010) Physicochemical characterization of cement kiln dust for potential reuse in acidic wastewater treatment. J Hazard Mater 173: 283-91.

20. Zaki NG, Kattab IA, Abdel-Monem NM (2007) Removal of some heavy metals by CKD leachate. J Hazard Mater 147: 21-7.

21. Pigaga A, Juskenas R, Virbalyte D, Klimantavviciute MG, Pakstas V (2005) The use of cement kiln dust for the removal of heavy metal ions from aqueous solutions. Trans Inst Met Finish 83: 210-4.

22. Hamad MA, Radwan AM, Heggo DA, Moustafa T (2016) Hydrogen rich gas production for catalytic gasification of biomass. Renewable Energy 85: 1290-300.

23. International Center for Diffraction Data (2018) Campus Boulevard, Newton Square, PA, USA.

24. Gadsden JA (1975) Infrared Spectra of Minerals and Related Inorganic Compounds, Butterworths, London.

25. Zaki MI, Knözinge H, Tesche B, Mekhemer GA (2006) Influence of phosphonation and phosphation on surface acid-base and morphological properties of CaO as investigated by in situ FTIR spectroscopy and electron microscopy. J Colloid Interface Sci 303: 9-17.

26. Zelic J, Rusic D, Kristulovic R (2002) Kinetic analysis of thermal decomposition of $\mathrm{Ca}(\mathrm{OH}) 2$ formed.during hydration of commercial Portland cement by DSC. J Therm Anal Calor 67: 613-22.

27. El-Didamony H, Heikal M, Khalil KhA, El-Sanhory A (2017) Pozzolanic activity of silica fume with lime. J Basic Environ Sci 4: 236-46. 


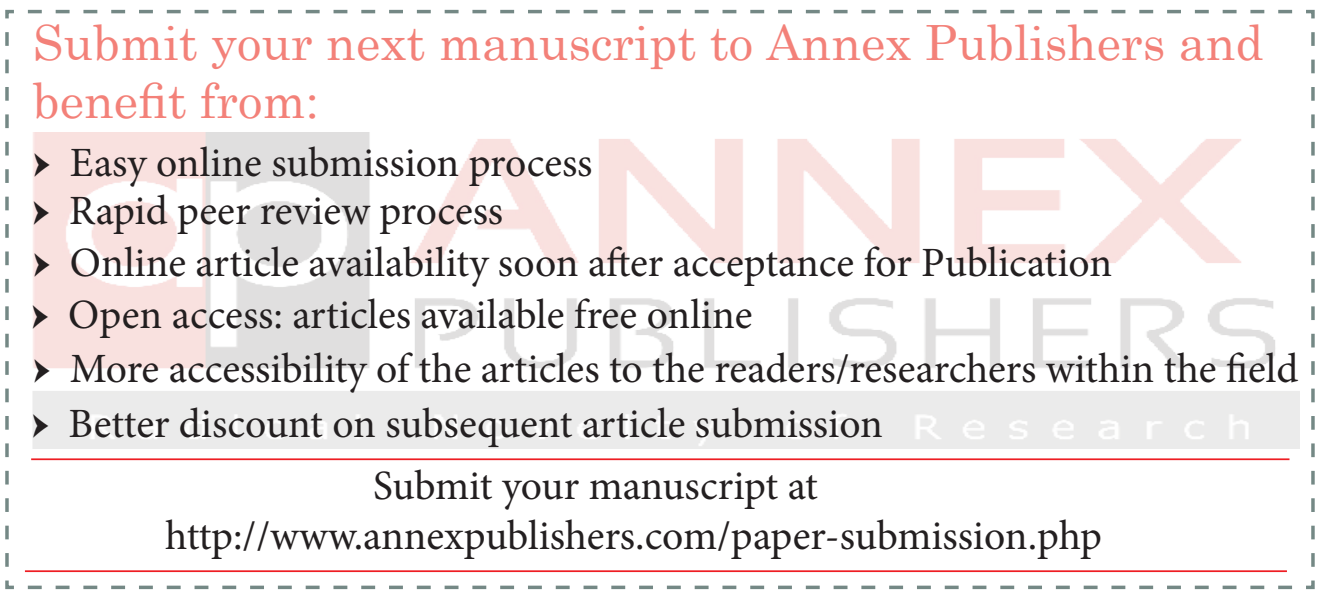

